\title{
Effect of Calcium Phytate on the Corrosion Behavior of 304 Stainless Steel as Coral Concrete Reinforcement in a 3.5\% Sodium Chloride solution
}

\author{
Pengfei Xu ${ }^{1,2}$, Xingguo Feng ${ }^{1,2}$, Xiangyu Lu ${ }^{1,2}{ }^{*}$, Cheng Chen ${ }^{1,2}$ \\ ${ }^{1}$ Key Laboratory of Ministry of Education for Coastal Disaster and Protection, Hohai University, \\ Nanjing 210098, China \\ ${ }^{2}$ College of Harbour, Coastal and Offshore Engineering, Hohai University, Nanjing, 210098, Jiangsu, \\ China \\ *E-mail: luxiangyu@hhu.edu.cn
}

doi: $10.20964 / 2020.12 .26$

Received: 2 August 2020 / Accepted: 24 September 2020 / Published: 31 October 2020

\begin{abstract}
The corrosion-inhibition behavior of calcium phytate on AISI 304 stainless steel in coral concrete is investigated by application of open circuit potential, linear polarization resistance, and electrochemical impedance spectroscopy. The results suggest that calcium phytate increases the open circuit potentials, polarization resistance, and charge transfer resistance of 304 stainless steel in chloride-contaminated coral concrete. Corrosion of the stainless steel rebar can be effectively suppressed by calcium phytate, which can be reduced by $90 \%$ via the addition of $0.1 \%$ of calcium phytate. Calcium phytate mainly promotes passivation and inhibits corrosion of the reinforced stainless steel, and it does not influence the coral concrete layers.
\end{abstract}

Keywords: coral concrete, stainless steel, corrosion inhibitor, electrochemical test, EIS

\section{$\underline{\text { FULL TEXT }}$}

(C) 2020 The Authors. Published by ESG (www.electrochemsci.org). This article is an open access article distributed under the terms and conditions of the Creative Commons Attribution license (http://creativecommons.org/licenses/by/4.0/). 